\title{
Evaluation of the Content of YouTube Videos about Vaginismus
}

\section{Yeliz KAYA (D) ${ }^{1}$, Coşkun KAYA, MD (D) $2^{*}$ and Pelin PALAS KARACA (D) ${ }^{3}$}

${ }^{1}$ Department of Nursing, Eskisehir Osmangazi University, Turkey

${ }^{2}$ Department of Urology, Eskisehir City Hospital, Turkey

${ }^{3}$ Department of Midwifery, Balikesir University, Turkey

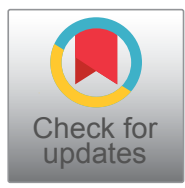

*Corresponding author: Coşkun KAYA, MD, Department of Urology, Eskisehir City Hospital, Address: 71 Evler Mah. Çavdarlar Sk. No: 26080, 26080 Odunpazari/Eskişehir, Turkey, Tel: 90-506-443-41-54

\begin{abstract}
Backgrounds: To evaluate the quality of information in YouTube videos about vaginismus.

Methods: A search for "vaginismus" was performed on YouTube in January 5, 2019. Two researchers watched and analyzed each video's overall information and scientific content and rated it as good, fair or poor as a co-decision. for their sources, suggestions and information contents (good, fair or poor).

Results: Of the three hundred videos viewed on YouTube, 106 videos were included and analyzed. Mean video length (mean \pm standard deviation) was $4.63 \pm 2.73$ minute. The information content was good only in 19 $(17.9 \%)$ of all videos while for a majority of them it was poor $(44.3 \% n=47)$. There was no relation between the reliability of the videos' contents and their viewings ( $p$ $=0.073$ ). Videos uploaded by health professionals were more reliable than those uploaded by laypersons $(p<$ 0.001).

Conclusions: The study suggests that the videos at YouTube could not be a reliable source of for patients with vaginismus. Health professions should be encouraged to upload more videos with good content and the patients with vaginismus should be warned about the unedited videos uploaded by laypersons and canalized to watch videos uploaded by health professions.
\end{abstract}

\section{Keywords}

Vaginismus, Source, YouTube

\section{Introduction}

Vaginismus (V), a reflex to avoid injury, is a psychological disorder manifested by fear and anxiety about penetration [1]. $\mathrm{V}$ is a poorly understood condition affecting approximately $5 \%$ to $17 \%$ of women worldwide [2] and one of the most female sexual disorders. Despite the high prevalence of this disorder, a definite etiology for $V$ could not be identified. With the uncertainty of the etiology, no standardized and etiology driven therapeutic interventions for $\mathrm{V}$ have been developed. Most recommendations for the treatment of $V$ are based on clinical experience and expert opinions instead of evidence provided by randomized clinical trials [3]. Behavioral sex therapy, cognitive behavioral sex therapy, pelvic floor physiotherapy, and pharmacological therapy, (local injections of botulin toxin or the use of psychiatric drugs), have been used as treatments for $V$ [4]. A meta-analysis of this treatment methods of $V$ showed that almost $80 \%$ of women with $V$ could benefit any type of treatment [5].

The studies reported that women with $\mathrm{V}$ could have a strong histrionic-hysterical personality [6] and show increased self-focused attention anxiety [7] as a result, these patients need more than the usual efforts to have painless intercourse. Some patients with $V$ could not to seek any type of treatment because of being embarrassed about the topic or some patients who do obtain therapy could need more advanced treatment from other clinicians, or want to hear about the problems from other people with V. The Internet, one of the most important information sources, could have been used to get health information as frequently at least as from their heath professional [8]. In this regard, YouTube, the third most-visited website [9] could have been preferred by $\mathrm{V}$ patients because it offers visual and audio information, compared with other social media platforms. Despite

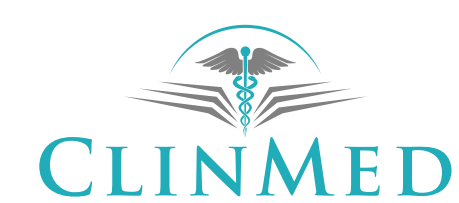

INTERNATIONAL LIBRARY

Citation: KAYA Y, KAYA C, KARACA PP (2019) Evaluation of the Content of YouTube Videos about Vaginismus. Int J Womens Health Wellness 5:109. doi.org/10.23937/2474-1353/1510109 Accepted: December 05, 2019: Published: December 07, 2019

Copyright: (c) 2019 KAYA Y, et al. This is an open-access article distributed under the terms of the Creative Commons Attribution License, which permits unrestricted use, distribution, and reproduction in any medium, provided the original author and source are credited. 
the advantages of YouTube as speed, ease, and the convenience to information; the most important disadvantage of this social media platform is that the information on this website is not regulated. Unmoderated and unregulated medical information could cause misleading decisions about the progress of an illness and treatment modality. To regulate the content of YouTube health videos, the validity of these videos were investigated by researchers previously [10]. To our knowledge, no study has analyzed the content of uploaded videos about V. Therefore, the aim of the present study was to assess the quality of YouTube information videos for $\mathrm{V}$.

\section{Material and Methods}

YouTube (http://www.youtube.com) was searched using the key word "vaginismus" on January 5, 2019 by two researchers. The first 300 videos were screened on the assumption that the majority of users would not go beyond the first 10 to 15 pages for a searched item. Two researchers who had sufficient experience in the diagnosis and management of $V$ independently assessed the videos. Disagreements between the researchers regarding the categorization of a particular video were resolved by discussing the issue until a consensus was reached. The videos were analyzed if they were in English, < 10 minutes in length, and had primary content related to $\mathrm{V}$. We did not analyze patient testimonials, videos without sound, videos not related to $\mathrm{V}$, videos that could not be accessed, news reports about an individual's $\mathrm{V}$ diagnosis or treatment, satire, or duplicated content. We extracted the title and duration of the video, the number of views, the author of the video, the affiliation of the author (layperson or medical professional) and the suggestions of the video (no suggestion, drug treatments, surgical treatments, behavioral treatments and alternative treatments).

Two researchers analyzed each video's overall information and scientific content and rated it as good, fair or poor as a co-decision. Due to the lack of standardized and validated means available to perform this kind of analysis, a set of predetermined criteria were used to grade the videos. A good video required accurate facts and discussion of both the advantages and disadvantages of the given video's suggestion. A fair rating would also be factually correct, but only discussed the advantages of a suggestion. A poor vid- eo would neither be factually correct nor include any discussion about any particular facets of $\mathrm{V}$.

Continuous variables were given as mean \pm standard deviation while categorical ones were given as number and percentage (\%). The normality was tested with the Shapiro-Wilk Test. The Mann-Whitney U Test was used for comparison between two different groups. While comparisons between three or more groups, the Kruskal-Wallis $\mathrm{H}$ Test was used. The Pearson Chi-Square and Fisher's Exact Test were used to analyze the crosstabs. Statistical analysis was done with IBM SPSS for Windows version 21.0 package (Armonk, NY: IBM Corp). The level of significance used was $\mathrm{p}<0.05$.

\section{Results}

Among the 22,700 videos, we analyzed the first 300. Of these, 106 (35.4\%) videos were included in the study while 194 (64.6\%) were excluded according to our study criteria (Table 1 ). The reasons for the exclusions are listed in detail in the flow chart. The mean video length (mean \pm standard deviation) was $4.63 \pm 2.73$ minute, mean time elapsed since posting was $890.52 \pm 550.60$ days and the mean views was $36171.12 \pm 174721.19$. Our ratings for videos showed that the information content was good only in 19 (17.9\%) of all videos while a majority of them were poor $(44.3 \% n=47)$. Fair videos constituted $37.8 \%$ ( $n$ $=40$ ) of the videos.

The Kruskal-Wallis test revealed that there was no relation between the reliability of the videos' contents and their viewings $(p=0.073$ ) (Table 2). While the majority of the videos about $\mathrm{V}$ were uploaded by a health professional (74.5\%); and according to the analysis of

Table 1: Excluded Videos.

\begin{tabular}{|l|l|}
\hline Reasons & $\mathbf{n}(\mathbf{\%})$ \\
\hline No sound & $2(1.0 \%)$ \\
\hline Patient testimonials & $33(17.0 \%)$ \\
\hline Not English & $56(28.9 \%)$ \\
\hline Not related to V & $16(8.2 \%)$ \\
\hline Not opened & $9(4.6 \%)$ \\
\hline News & $12(6.2 \%)$ \\
\hline Duration $>10$ min. & $66(34.0 \%)$ \\
\hline Total & $194(100.0 \%)$ \\
\hline
\end{tabular}

Table 2: The relationship between physicians rated content and view/source of the YouTube videos.

\begin{tabular}{|c|c|c|c|c|c|c|}
\hline & \multirow[b]{2}{*}{$\mathbf{n}$} & \multirow{2}{*}{$\begin{array}{l}\text { View } \\
\text { Mean } \pm \text { St.Dv. }\end{array}$} & \multirow{2}{*}{$\mathbf{p}^{\mathbf{a}}$} & \multicolumn{2}{|l|}{ Source } & \multirow{2}{*}{$\mathbf{p}^{\mathbf{b}}$} \\
\hline & & & & Non-health Professions & Health Professions & \\
\hline Poor & 47 & $16528.17 \pm 62002.68$ & \multirow{4}{*}{0.073} & $27(100.0 \%)$ & $20(25.3 \%)$ & \multirow{4}{*}{$<0.001$} \\
\hline Fair & 40 & $70563.15 \pm 274875.98$ & & $0(0.0 \%)$ & $40(50.6 \%)$ & \\
\hline Good & 19 & $12357.31 \pm 17.654 .71$ & & $0(0.0 \%)$ & $19(24.1 \%)$ & \\
\hline Total & 106 & $36171.12 \pm 174721.19$ & & $27(100.0 \%)$ & $79(100.0 \%)$ & \\
\hline
\end{tabular}

a. Kruskal Wallis H Test; b. Pearson Exact Chi-Square. 
Table 3: Suggestions of the videos according to their sources.

\begin{tabular}{|l|l|l|l|l|l|l|l|}
\hline Suggestions & $\begin{array}{l}\text { No } \\
\text { suggestion }\end{array}$ & $\begin{array}{l}\text { Any type of } \\
\text { Drug }\end{array}$ & $\begin{array}{l}\text { Any type of } \\
\text { psychotherapy }\end{array}$ & $\begin{array}{l}\text { Alternative } \\
\text { treatments }\end{array}$ & $\begin{array}{l}\text { Combined } \\
\text { treatments }\end{array}$ & Total \\
\hline Non-health Profesions & $19(47.5 \%)$ & $0(0.0 \%)$ & $0(0.0 \%)$ & $8(19.4 \%)$ & $0(0.0 \%)$ & $27(24.8 \%)$ \\
\hline Health Profesions & $21(52.5 \%)$ & $8(100.0 \%)$ & $9(100.0 \%)$ & $29(80.6 \%)$ & $12(100.0 \%)$ & $79(75.2 \%)$ & $<0.001$ \\
\hline Total & $40(100.0 \%)$ & $8(100.0 \%)$ & $9(100.0 \%)$ & $36(100.0 \%)$ & $12(100.0 \%)$ & $106(100.0 \%)$ \\
\hline
\end{tabular}

a. Pearson Exact Chi-Square.

videos rated by us, the videos uploaded by health professionals were more reliable than those uploaded by non-health professionals $(p<0.001)$. More videos by non-health professionals (73.0\%) did not suggest any treatment methods; while types of treatment were discussed in almost $75 \%$ of the videos uploaded by health professionals (Table 3 ).

\section{Discussion}

YouTube, a website which is used as tool for information and is accessed by patients and families, has more than 1 billion users [11]. It contains videos uploaded by various websites unrelated to medical institutions or physician groups. An editorial process does not control the content and reliability of the uploaded videos, and most videos do not contain information about the origin or authorship. Unmoderated YouTube videos could cause the patients to learn false information rather than accurate information.

There have been different results about the relation between the source type of the videos and the number of views received. A study found that no significant correlation existed between the content and the number of views or the ratings given by YouTube viewers [12]. In our study we found that the YouTube viewers watched all videos regardless of their physician rated content. Likewise, Basch, et al. analyzed 100 YouTube videos about lead poisoning and reported that the number of views for the videos was not statistically different from the source type [13]. Sahin, et al. examined the videos about retinitis pigmentosa and reported that the mean view of useful videos was significantly higher compared to those of the misleading videos $(p=0.022)$ [14]. As the results of Sahin, et al. [14], Sood, et al. reported that useful videos were rated and viewed significantly higher than misleading videos [15]. In contrast, Esen, et al. concluded that the number of total views was higher for the misleading information group [16].

In our study, $25 \%$ of the videos included in to the study were uploaded by non-health professions, all these videos were rated as poor by the researchers and the majority of these videos did not suggest any type of treatment. Although the source of $75 \%$ of the videos were from health professionals, only almost $25 \%$ of these videos were grouped as good video and did not suggest any type of treatment like the vid- eos uploaded by non health professions. This is a rate that is comparable to similar studies of information found on YouTube for other diseases, such as food allergies [17], inflammatory bowel disease (24\%) [18], anorexia (29\%) [19], and rheumatoid arthritis (30\%) [20] Lena, et al. analyzed the videos on YouTube about lingual orthodontic treatment that $30.7 \%$ $(n=32)$ of the videos were included high content about treatment and that most videos were uploaded by a layperson $(58.7 \%, n=61)$ [21]. Sahin, et al. reported that most of the useful videos about retinitis pigmentosa were uploaded by healthcare professionals (75\%) and these videos were more useful compared to those from non-healthcare professionals ( $p=0.029$ ) [14]. Esen, et al. evaluated the content and comments of breast self-examination videos on YouTube [16]. They found that of 200 videos initially included in the study, $33(37.9 \%)$ were classified as useful and $54(62 \%)$ as containing misleading information. The reliability, content and quality scores of the videos in the useful information group were higher. The majority $(70.6 \%)$ of the videos in the misleading information group had been uploaded by an individual user. A study of 117 YouTube videos about dental implants performed in 2018 reported that almost more than half of the videos were uploaded by health care professionals and misleading information existed in $30.1 \%$ of the videos [22].

The first limitation of this study was that the videos included in the analysis were taken from just one point of time and all videos were evaluated by an unvalidated method, which was developed by researchers. In addition, the search in this study was limited to only YouTube, despite other websites, such as those from medical organizations and other health professional societies, being available.

\section{Conclusion}

According to our results and literature; there are a significant number of videos on YouTube which give misleading information about illnesses and their treatment methods. Unfortunately, many poor quality videos were uploaded by health or non-health professions which might have dangerous consequences for users. To save patients from this misleading information, health professionals should be encouraged to upload more videos with good content and patients with $\mathrm{V}$ 
should be warned about unedited videos uploaded by laypersons and directed to watch videos uploaded by health professionals.

\section{Source of Support}

None.

\section{References}

1. Rosenbaum T (2013) An integrated mindfulness-based approach to the treatment of women with sexual pain and anxiety: Promoting autonomy and mind/body connection. Sexual and Relationship Therapy 28: 1-2.

2. Lahaie MA, Boyer S, Amsel R, Khalifé S, Binik YM (2010) Vaginismus : A review of the literature on classification/diagnosis, etiology, andtreatment. Woman's Health 6: 705719.

3. Fugl-Meyer KS, Bohm-Starke N, Damsted Petersen C Fugl-Meyer A, Parish S, et al. (2013) Standard operating procedures for female genital sexual pain. J Sex Med 10: 83-93.

4. Melnik T, Hawton K, McGuire $H$ (2012) Interventions for vaginismus. Cochrane Database Syst Rev 12: CD001760.

5. Maseroli E, Scavello I, Rastrelli G, Limoncin E, Cipriani S, et al. (2018) Outcome of medical and psychosexual interventions for vaginismus: A systematic review and meta-analysis. J Sex Med 15: 1752-1764.

6. Maseroli E, Scavello I, Cipriani S, Palma M, Fambrini M, et al. (2017) Psychobiological correlates of vaginismus: An exploratory analysis. J Sex Med 14: 1392-1402.

7. Weijmar Schultz W, Basson R, Binik Y, Eschenbach D, Wesselmann U, et al. (2005) Women's sexual pain and its management. J Sex Med 2: 301-316.

8. Bernstein KI, Promislow S, Carr R, Rawsthorne P, Walker $J R$, et al. (2011) Information needs and preferences of recently diagnosed patients with inflammatory bowel disease. Inflamm Bowel Dis 26: 525-531.

9. Stellefson M, Chaney B, Ochipa K, Chaney D, Haider Z, et al. (2014) YouTube as a source of chronic obstructive pulmonary disease patient education: A social media content analysis. Chron Respir Dis 11: 61-71.
10. Azer S (2014) Understanding pharma cokinetics: Are YouTube videos a useful learning resource? Eur Rev Med Pharmacol Sci. 18: 1957-1967.

11. (2019) YouTube for Press Pages.

12. Steinberg PL, Wason S, Stern JM, Deters L, Kowal B, et al. (2010) YouTube as source of prostate cancer information. Urology 75: 619-622.

13. Basch $\mathrm{CH}$, Jackson AM, Yin J, Hammond RN, Adhikari A, et al. (2017) English language YouTube videos as a source of lead poisoning-related information: a cross-sectional study. Int J Occup Environ Health 23: 222-227.

14. Şahin A, Şahin M, Türkcü FM (2018) YouTube as a source of information in retinopathy of prematurity. Ir J Med Sci 188: 613-617.

15. Sood A, Sarangi S, Pandey A, Murugiah K (2010) YouTube as a source of information on kidney stone disease. Endourology and Stones. Urology 77: 558-562.

16. Esen E, Aslan M, Sonbahar BÇ, Kerimoğlu RS (2019) YouTube English videos as a source of information on breast self-examination. Breast Cancer Res Treat 173: 629-635.

17. Reddy K, Kearns M, Alvarez-Arango S, Carrillo-Martin I, Cuervo-Pardo N, et al. (2018) YouTube and food allergy: An appraisal of the educational quality of information. Pediatr Allergy Immunol 29: 410-416.

18. Mukewar S, Mani P, Wu X, Lopez R, Shen B (2013) YouTube and inflammatory bowel disease. J Crohns Colitis 7: 392-402.

19. Syed-Abdul S, Fernandez-Luque L, Jian WS, Li YC, Crain $S$, et al. (2013) Mis leading health-related information promoted through video-based social media: anorexia on YouTube. J Med Internet Res 15.

20. Singh AG, Singh S, Singh PP (2012) YouTube for information on rheumatoid arthritis--a wake up call? J Rheumatol 39: 899-903.

21. Lena $Y$, Dindaroğlu F (2018) Lingual orthodontic treatment: A YouTube $^{\mathrm{TM}}$ video analysis. Angle Orthod 88: 208-214.

22. Abukaraky A, Hamdan AA, Ameera MN, Nasief M, Hassona Y (2018) Quality of YouTube TM videos on dental implants. Med Oral Patol Oral Cir Bucal 23: 463-468. 